\title{
FARMACOPEIA ODONTOLÓGICA DOS INDÍGENAS BRASILEIROS: UMA REVISÃO SISTEMÁTICA ACERCA DO USO E BIOATIVIDADE
}

DEYVISON RHUAN VASCO-DOS-SANTOS ${ }^{1}$

$U N E B$

VANESSA CARDOSO PEREIRA ${ }^{2}$

$U N E B$

ROSÂNGELA MARIA PEREIRA VALÕES ${ }^{3}$

$U N E B$

ARTUR GOMES DIAS-LIMA ${ }^{4}$

$U N E B$

ANDERSON DA COSTA ARMSTRONG 5

$U N E B$

CARLOS ALBERTO BATISTA DOS SANTOS ${ }^{6}$

$U N E B$

RESUMO: Comunidades indígenas são detentoras de um rico conhecimento acerca do uso de plantas medicinais empregadas em seus complexos sistemas terapêuticos. Entretanto, apesar do avanço nas pesquisas etnomedicobotânicas que visam compreender a tríplice homem-saúdeflora, as insuficientes informações sobre o tema fragilizam o entendimento do real perfil de saúde

\footnotetext{
${ }^{1}$ Mestrando em Ecologia Humana e Gestão Socioambiental (Universidade do Estado da Bahia). E-mail: deyvison.biouneb@gmail.com

${ }^{2}$ Mestranda em Ecologia Humana e Gestão Socioambiental (Universidade do Estado da Bahia). E-mail: enf_vanessa@hotmail.com

${ }^{3}$ Mestranda em Ecologia Humana e Gestão Socioambiental (Universidade do Estado da Bahia). E-mail: rosavaloes@hotmail.com

${ }^{4}$ Doutor em Biologia Parasitária (Fundação Oswaldo Cruz). Professor Pleno da Universidade do Estado da Bahia, Departamento Ciências da Vida, Campus I e Professor Adjunto da Escola Bahiana de Medicina e Saúde Pública. E-mail: agdlima@uneb.br

${ }^{5}$ Doutor em Medicina e Saúde Humana (Escola Bahiana de Medicina e Saúde Pública). Professor da Universidade do Estado da Bahia e da Universidade Federal do Vale do São Francisco. E-mail: armstrong_ac@yahoo.com

${ }^{6}$ Doutor em Etnobiologia e Conservação da Natureza, Universidade do Estado da Bahia, Coordenador do Programa de Pós-Graduação em Ecologia Humana e Gestão Socioambiental. E-mail: cacobatista@yahoo.com.br
} 
dessas populações, inclusive sobre a saúde bucal. Desse modo, este estudo teve como objetivo realizar o levantamento de plantas medicinais utilizadas por comunidades indígenas brasileiras para saúde bucal, bem como investigar a bioatividade descrita para as espécies encontradas através de uma revisão sistemática. Os trabalhos acessados mencionam 17 etnoespécies com diferentes partes utilizadas, formas de preparo e modos de uso. Entre estas, 29\% possuem propriedades descritas para odontologia, as quais corroboram a indicação tradicional, $47 \%$ possuem propriedades médicas que justificam a utilização, como antimicrobiana e antiinflamatória, enquanto $24 \%$ não possuem potenciais para saúde disponível na literatura acessada. O levantamento endossa a riqueza do conhecimento botânico medicinal indígena do Brasil e sua eficácia na profilaxia e tratamento bucal, porém evidencia a necessidade de mais estudos direcionados à área.

PALAVRAS-CHAVE: conhecimento tradicional; bioeficácia, saúde bucal; povos indígenas.

ABSTRACT: Indigenous communities have a traditional knowledge about the use of medicinal plants in their complex therapeutic systems. However, despite the advances in ethno-medicalbotanical research that aims to understand the man-health-flora triple relation, the insufficiency of information about the theme weakens the understanding of the real health profile of these populations, including for oral health. Thus, this research aims to compile medicinal plants used by Brazilian Indigenous communities for oral health, as well as to investigate the bioactivity described for the species found through a systematic review. The accessed work mentioned 17 ethnospecies with diverse practical uses and forms of preparation. Among these, 29\% have described properties for oral health, which corroborate to the traditional indication, $47 \%$ have other medical properties that justify their use, such as antimicrobial and anti-inflammatory mechanisms, and $24 \%$ have no health potential available in the literature. The collection of information endorses the richness of the Indigenous medicinal botanical knowledge in Brazil and its effectiveness in oral health, but it evidences the need of additional studies in the field

KEYWORDS: traditional knowledge; bioefficacy; oral health; Indigenous peoples.

\section{Introdução}

Os saberes indígenas sobre saúde estão embasados em métodos próprios de interpretação, prevenção, tratamento e cura de patologias, os quais se associam a fatores socioculturais, históricos e ambientais (BERTANHA et al., 2012; ALVES FILHO; SANTOS; VETTORE, 2014). Dentre os elementos utilizados no combate às doenças pelos índios, destaca-se a flora, em virtude da estreita relação destes grupos com os recursos naturais, sendo o arcabouço terapêutico fruto de um dinâmico e amplo processo de validação cultural (HAVERROTH, 2013).

No Brasil, o conhecimento em saúde dos povos nativos é um dos elementos que mais resistiram ao tempo e influência o uso de plantas medicinais em todo território nacional. De fato, estima-se que anteriormente à chegada dos colonizadores europeus no século XVI, cerca de duas mil espécies já seriam utilizadas pelos povos nativos (LUCIANO, 2006; BORBA; MACEDO, 2006). O interesse em compreender as práticas 
de cura tradicionais estimulou o desenvolvimento de várias pesquisas etnomedicobotânicas. Entretanto, há poucas informações sobre os saberes empregados na saúde bucal, a qual configura-se como indissociável para saúde geral (ARROYAVE; ISÁGAMA, 2012; BARBOSA; NASCIMENTO, 2017).

Com relação à saúde bucal dos índios brasileiros, especialmente sobre a cárie, há ausência de subsídios que permitam avaliar com clareza o perfil epidemiológico, havendo dados restritos apenas para algumas etnias. Porém, o contato com os não índios, introdução de alimentos industrializados nas comunidades, bem como as mudanças sociais e econômicas, são fatores que repercutem negativamente na saúde oral desses povos (ARANTES, 2005; BASTA; ORELLANA; ARANTES, 2012).

As pesquisas odontológicas conduzidas junto aos povos indígenas são, em sua maioria, a respeito da morfologia dentária, marcadores fisiológicos e defeitos de esmaltes (ARANTES, 2005). Inquéritos realizados com os Baniwa (CARNEIRO et al., 2008), Tupiniquim e Guarani (ALENCAR et al., 2011), mostram um alto índice de cárie para o primeiro grupo e presença de fluorose dentária nos demais, alertando assim para a necessidade de estratégias de atenção, promoção e prevenção em saúde bucal que minimizem estes agravos. Contudo, estas ações precisam considerar as particularidades socioculturais de cada etnia para que sejam efetivas, o que inclui a cosmovisão de saúde e doença, bem como os diversos elementos empregados em seus sistemas medicinais, a exemplo dos vegetais.

No estudo de Aleluia et al. (2015) foram levantadas 132 plantas que auxiliam no tratamento de afecções odontológicas, sendo o cravo da Índia (Syzygium aromaticun L.), a camomila (Matricaria recutita L.), a malva (Malva sylvestris L.) e a unha de gato [Uncaria tomentosa (Willd. ex Roem. \& Schult.) DC.] os fitoterápicos mais utilizados e com benefícios comprovados. Nesse contexto, diante da importância da difusão dos saberes indígenas, dos poucos dados sobre a saúde bucal nessas populações e da eficácia do uso de plantas medicinais para a odontologia, este trabalho teve como objetivo realizar o levantamento da flora odontológica utilizada na saúde bucal por povos indígenas do Brasil e da bioatividade descrita para as espécies.

\section{Metodologia}

Nesta revisão sistemática, a coleta de dados foi organizada em duas etapas: I) levantamento etnomedicobotânico das espécies utilizadas na saúde oral por comunidades indígenas do Brasil; II) busca da bioatividade para as espécies encontradas na fase anterior. A primeira baseou-se na análise dos dados presentes na revisão conduzida por Rocha e Marisco (2016) intitulada Estudos etnobotânicos em comunidades indígenas no Brasil. Entretanto, considerando que a pesquisa anterior selecionou 
artigos publicados até 2015, foi feita uma revisão complementar empregando a mesma metodologia de 2016 até agosto de 2017.

Para busca da bioatividade realizou-se uma revisão nas bases de dados Google acadêmico, Pubmed, Science Direct e Scielo, utilizando como descritores os nomes científicos das espécies vegetais. Em cada periódico foram verificados 250 estudos, quando disponíveis, totalizando um esforço de busca de mil trabalhos por planta, sem restrição quanto ao ano ou idioma de publicação. Os critérios de inclusão e exclusão são apresentados na Figura 1. Nos estudos em que apenas o território indígena foi informado, os nomes das etnias foram verificados no site da Fundação Nacional do Índio (FUNAI, 2017) e a padronização das informações botânicas foi realizada em consulta ao The International Plant Names Index (IPNI) e a Flora do Brasil, adotando as classificações deste último em casos de divergência.

FIGURA 1. Fluxograma de seleção de artigos para revisão acerca da bioatividade da flora odontológica indicadas por comunidades indígenas brasileiras.

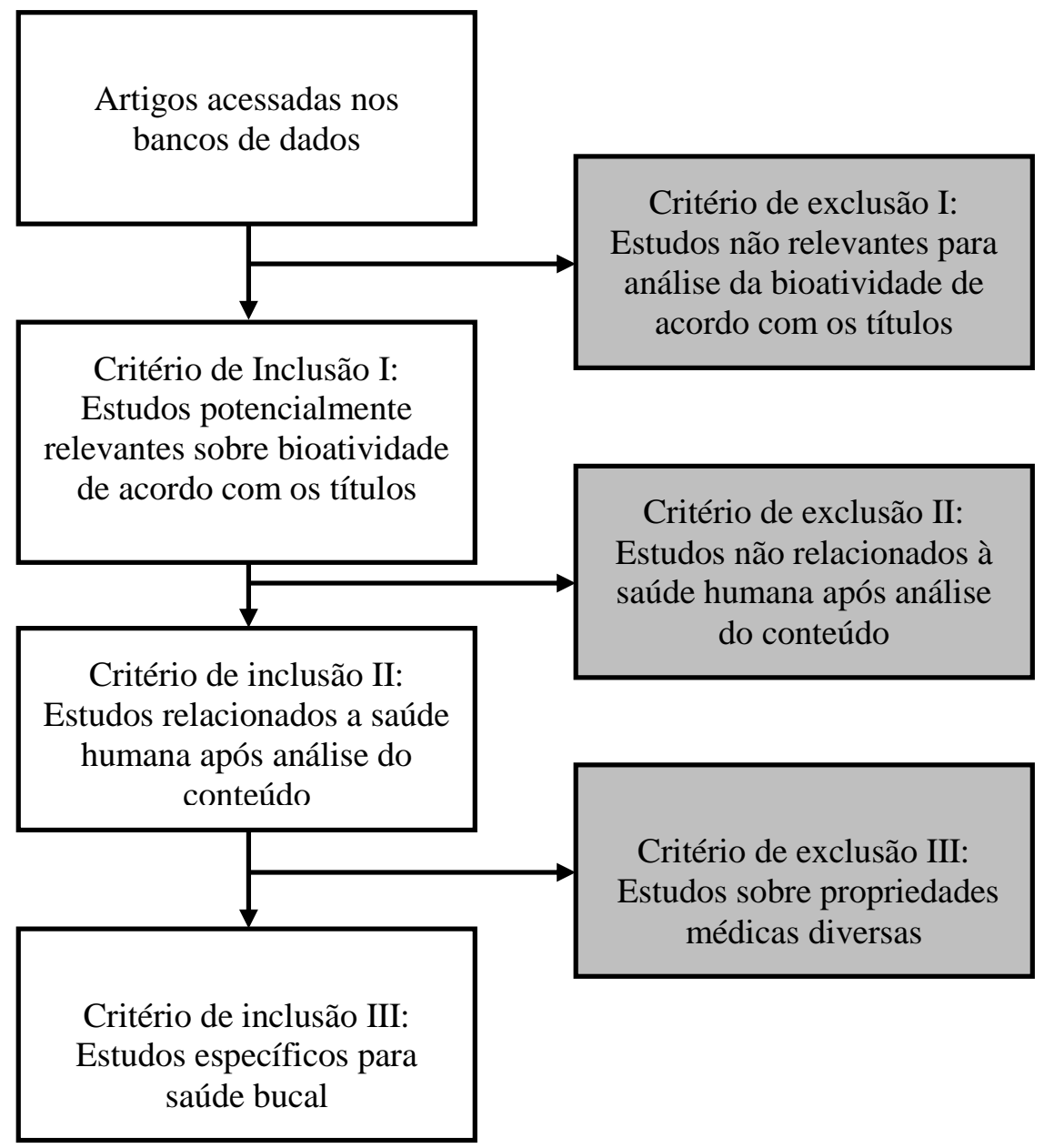




\section{Resultados: caracterização dos trabalhos}

Dentre as 30 pesquisas etnobotânicas levantadas por Rocha e Marisco (2016), 17\% citam espécies medicinais utilizadas para saúde oral, realizados com as etnias Kaingang (terras Xapecó e Ventarra Alta), Guarani Mbya (terras de Irapuá, Itaúba e Salto Grande do Jucuí) e Fulni-ô (terra indígena Fulni-ô) (Tabela 1). Enquanto na revisão complementar foram selecionados quatro artigos (KFFURI et al., 2016; SANTOS et al., 2016; SANTOS-LIMA et al., 2016; OLIVEIRA; BRAGA, 2017), totalizando 34 trabalhos etnobotânicos com indígenas no Brasil. Porém, nos estudos publicados nos últimos dois anos não haviam dados sobre o uso de plantas medicinais para profilaxia ou tratamento bucal.

De acordo com o IBGE (2010) a região Norte possui maior número de indígenas (305.873), seguida pelo Nordeste (208.691), Centro-Oeste (130.494), Sudeste (97.970) e Sul (74.475), havendo em todo o país cerca de 305 etnias. Apesar do Sul ser a região menos populosa, possui o maior número de trabalhos com ênfase em plantas medicinais $(n=12)$, superando os estados do Nordeste que até 2015 somavam o maior número de pesquisas na área $(n=10)$ e após a revisão complementar totalizou 11 estudos. A respeito dos trabalhos sobre ervas usadas para saúde bucal, $75 \%$ foram realizados no Sul e $25 \%$ no Nordeste. O baixo quantitativo de estudos com dados para saúde oral está possivelmente associado aos seus objetivos, por avaliarem o uso de plantas medicinais para outras doenças ou por se tratarem de levantamentos generalistas.

TABELA 1. Estudos etnobotânicos com indígenas no Brasil referenciados por Rocha e Marisco (2016) que apresentam dados sobre plantas medicinais utilizadas na saúde bucal.

\begin{tabular}{|c|c|c|c|}
\hline $\begin{array}{l}\text { Autores } \\
\text { (Ano) }\end{array}$ & Título & $\begin{array}{c}\text { Tipologia } \\
\text { textual }\end{array}$ & $\begin{array}{c}\text { Universidade/ } \\
\text { Revista }\end{array}$ \\
\hline $\begin{array}{l}\text { Haverroth } \\
\text { (1997) }\end{array}$ & $\begin{array}{l}\text { Kaingang um estudo etnobotânico: O } \\
\text { uso e a classificação das plantas na área } \\
\text { indígena Xapecó (Oeste de SC) }\end{array}$ & Dissertação & $\begin{array}{l}\text { Universidade Federal de } \\
\text { Santa Catarina - UFSC }\end{array}$ \\
\hline $\begin{array}{l}\text { Silva } \\
(2003)\end{array}$ & $\begin{array}{l}\text { Etnobotânica dos índios Fulni-ô } \\
\text { (Pernambuco, Nordeste do Brasil) }\end{array}$ & Tese & $\begin{array}{l}\text { Universidade Federal de } \\
\text { Pernambuco - UFPE }\end{array}$ \\
\hline $\begin{array}{l}\text { Lindenmaier } \\
\text { e Putzke } \\
\text { (2011) }\end{array}$ & $\begin{array}{l}\text { Estudo Etnobotânico em três } \\
\text { comunidades Mbya/Guarani na região } \\
\text { central do Rio Grande do Sul, Brasil }\end{array}$ & Artigo & $\begin{array}{l}\text { Caderno de Pesquisa, } \\
\text { Série Biologia }\end{array}$ \\
\hline $\begin{array}{l}\text { Coan e } \\
\text { Matias } \\
(2014)\end{array}$ & $\begin{array}{l}\text { A Utilização das plantas medicinais pela } \\
\text { comunidade indígena de Ventarra Alta- } \\
\text { RS }\end{array}$ & Artigo & $\begin{array}{l}\text { Revista de Saúde Pública e } \\
\text { Biologia }\end{array}$ \\
\hline $\begin{array}{l}\text { Mendes } \\
(2015)\end{array}$ & $\begin{array}{l}\text { O Uso das ervas medicinais na } \\
\text { atualidade Kaingang da terra indígena } \\
\text { Xapecó, Santa Catarina, Brasil }\end{array}$ & Monografia & $\begin{array}{l}\text { Universidade Federal de } \\
\text { Santa Catarina - UFSC }\end{array}$ \\
\hline
\end{tabular}




\section{Flora dos indígenas brasileiros utilizada na saúde oral}

O total de dezessete etnoespécies medicinais foram citadas para saúde bucal nos trabalhos selecionados (Tabela 1). Entre estas, duas não foram identificadas cientificamente, duas a nível de gênero e treze a nível específico, distribuídas em doze famílias (Tabela 2). A família Leguminosae foi a mais representativa, com três espécies, seguida das famílias Anacardiaceae e Rhamnaceae, com duas espécies cada. A maioria dos vegetais (94\%) são citados por um único trabalho, salvo o guiné (Petiveria alliacea L.), indicado por duas aldeias Kaingang-Xapecó e Kaingang-Ventarra Alta.

TABELA 2. Plantas medicinais utilizadas na saúde bucal por povos indígenas brasileiros de acordo com os trabalhos referenciados na revisão de Rocha e Marisco (2016). D.N.I.: Dados Não Informados.

\begin{tabular}{|c|c|c|c|c|c|}
\hline $\begin{array}{c}\text { Família / } \\
\text { Nome científico }\end{array}$ & Etnoespécie & Indicação & $\begin{array}{c}\text { Parte } \\
\text { utilizada }\end{array}$ & $\begin{array}{l}\text { Forma } \\
\text { de uso }\end{array}$ & $\begin{array}{c}\text { Povos } \\
\text { indígenas } \\
\end{array}$ \\
\hline \multicolumn{6}{|l|}{ Anacardiaceae } \\
\hline $\begin{array}{l}\text { Myracrodruon } \\
\text { urundeuva Allemão }\end{array}$ & Aroeira & Dor de dente & Casca & $\begin{array}{l}\text { Chá das } \\
\text { raspas }\end{array}$ & Fulni-ô \\
\hline $\begin{array}{l}\text { Schinus terebinthifolius } \\
\text { Raddi }\end{array}$ & $\begin{array}{c}\text { Aroeira } \\
\text { vermelha }\end{array}$ & $\begin{array}{c}\text { Sapinho na boca } \\
\text { de criança }\end{array}$ & Folha & Infusão & Guarani - Mbya \\
\hline \multicolumn{6}{|l|}{ Arecaceae } \\
\hline $\begin{array}{l}\text { Syagrus romanzoffiana } \\
\text { (Cham.) Glassman }\end{array}$ & $\begin{array}{l}\text { Coqueiro - } \\
\text { jerivá }\end{array}$ & Dor de dente & Raiz & Infusão & Guarani-Mbya \\
\hline \multicolumn{6}{|l|}{ Cannabaceae } \\
\hline $\begin{array}{l}\text { Celtis ehrenbergiana } \\
\text { (Klotzsch) Liebm. }\end{array}$ & Esporão-de-galo & Dor de dente & Folha & Infusão & Guarani - Mbya \\
\hline \multicolumn{6}{|l|}{ Poaceae } \\
\hline Coix lacryma-jobi L. & $\begin{array}{l}\text { Rosário-de- } \\
\text { lavoura }\end{array}$ & Dor de dente & D.N.I. & D.N.I. & $\begin{array}{l}\text { Kaingang - } \\
\text { Xapecó }\end{array}$ \\
\hline \multicolumn{6}{|l|}{ Leguminosae } \\
\hline $\begin{array}{l}\text { Amburana cearensis } \\
\text { (Allemão) A.C.Sm. }\end{array}$ & $\begin{array}{l}\text { Emburana de } \\
\text { cheiro }\end{array}$ & Dor de dente & Casca & $\begin{array}{l}\text { Raspas em } \\
\text { água }\end{array}$ & Fulni-ô \\
\hline $\begin{array}{l}\text { Mimosa tenuiflora } \\
\text { (Willd.) Poir. }\end{array}$ & Jurema preta & Dor de dente & Casca & $\begin{array}{l}\text { Chá das } \\
\text { raspas }\end{array}$ & Fulni-ô \\
\hline D.N.I. & Cana-frista & Dor de dente & Casca & D.N.I. & $\begin{array}{l}\text { Kaingang - } \\
\text { Xapecó }\end{array}$ \\
\hline \multicolumn{6}{|l|}{ Malvaceae } \\
\hline Malva sp. & Malva & Dor de dente & D.N.I. & D.N.I. & $\begin{array}{l}\text { Kaingang - } \\
\text { Xapecó }\end{array}$ \\
\hline \multicolumn{6}{|l|}{ Phytolaccaceae } \\
\hline Petiveria alliacea $\mathrm{L}$. & Guiné & Dor de dente & $\begin{array}{l}\text { Casca; } \\
\text { Folha }\end{array}$ & $\begin{array}{c}\text { Chá } \\
\text { (Gargarejo) }\end{array}$ & $\begin{array}{c}\text { Kaingang - } \\
\text { Xapecó; } \\
\text { Kaingang - } \\
\text { Ventarra Alta }\end{array}$ \\
\hline
\end{tabular}




\begin{tabular}{|c|c|c|c|c|c|}
\hline \multicolumn{6}{|l|}{ Piperaceae } \\
\hline $\begin{array}{l}\text { Pothomorphe } \\
\text { umbellata (L.) Miq. }\end{array}$ & Pariparoba & $\begin{array}{c}\text { Infecção da } \\
\text { gengiva e dor de } \\
\text { dente }\end{array}$ & $\begin{array}{l}\text { Raiz, } \\
\text { Folha }\end{array}$ & Compressa & $\begin{array}{l}\text { Kaingang - } \\
\text { Ventarra Alta }\end{array}$ \\
\hline \multicolumn{6}{|l|}{ Rhamnaceae } \\
\hline $\begin{array}{l}\text { Scutia buxifolia } \\
\text { Reissek }\end{array}$ & Curunilha & Dor de dente & $\begin{array}{c}\text { Folha e } \\
\text { Casca }\end{array}$ & Infusão & Guarani - Mbya \\
\hline Ziziphus joazeiro Mart. & Joazeiro & $\begin{array}{l}\text { Limpeza do } \\
\text { dente }\end{array}$ & Casca & $\begin{array}{c}\text { Friccionar as } \\
\text { raspas no } \\
\text { dente }\end{array}$ & Fulni-ô \\
\hline \multicolumn{6}{|l|}{ Rosaceae } \\
\hline $\begin{array}{l}\text { Prunus myrtifolia (L.) } \\
\text { Urb. }\end{array}$ & $\begin{array}{l}\text { Pessegueiro-do- } \\
\text { mato }\end{array}$ & Dor de dente & Folha & Infusão & Guarani-Mbya \\
\hline \multicolumn{6}{|l|}{ Solanaceae } \\
\hline $\begin{array}{l}\text { Solanum mauritianum } \\
\text { Scop. }\end{array}$ & Fumo-brabo & Dor de dente & $\begin{array}{l}\text { Folha e } \\
\text { Raiz }\end{array}$ & Infusão & $\begin{array}{l}\text { Guarani - } \\
\text { Mbya }\end{array}$ \\
\hline \multicolumn{6}{|l|}{ Verbenaceae } \\
\hline Lippia sp. & $\begin{array}{l}\text { Alecrim de } \\
\text { caboclo }\end{array}$ & Dor de dente & Folha & $\begin{array}{c}\text { Chá e } \\
\text { gargarejo }\end{array}$ & Fulni-ô \\
\hline \multicolumn{6}{|l|}{ D.N.I. } \\
\hline D.N.I. & Batata doce & $\begin{array}{l}\text { Inflamação de } \\
\text { gengiva }\end{array}$ & D.N.I. & D.N.I. & D.N.I. \\
\hline
\end{tabular}

A principal indicação de uso das etnoespécies foi dor de dente (83\%), seguida por problemas na gengiva (12\%), sapinho na boca de criança e limpeza dos dentes ( $5 \%$ cada), sendo o chá o método de preparo mais comum (57\%). Entre as partes vegetais utilizadas, destaca-se o uso de folha (46\%), sobre casca (40\%) e raiz (16\%). Para o guiné ( $P$. alliacea), ariparoba [Pothomorphe umbellata (L.) Miq.], curunilha (Scutia buxifolia Reissek), bem como para o fumo-brabo (Solanum mauritianum Scop.), são utilizadas mais de uma estrutura. Coan e Matias (2014) explicam que entre os Kaingang da terra indígena Ventarra-Alta, a maior utilização de folhas deve estar associada a disponibilidade deste recurso e devido a facilidade de colheita, além de ser um aspecto favorável para conservação das espécies.

\section{Bioatividade da flora utilizada na saúde oral por comunidades indígenas brasileiras}

Foram acessados 6.955 artigos nos bancos de dados; 597, através do mapeamento de título, eram potenciais para estudos de bioatividade. Destes, 328 não tinham associação com saúde humana e 269 possuíam. 
Nesta última categoria, somente 33 trabalhos descreviam propriedades associadas à saúde bucal, para aroeira $(n=7)$, aroeira vermelha $(n=5)$, malva $(n=9)$, joazeiro $(n=7)$ e alecrim $(n=5)$, não sendo encontrados pesquisas com aplicações odontológicas para as demais espécies.

\section{Aroeira (Myracrodruon urundeuva Allemão)}

Myracrodruon urundeuva é uma árvore nativa do Brasil, com ocorrência nos domínios fitogeográficos de Caatinga, Cerrado e Mata Atlântica, conhecida popularmente como almecega, aroeira, aroreira-doSertão e urundeuva (SILVA-LUZ; PIRANI, 2015). A planta é utilizada na medicina tradicional para inflamação, evitar gravidez (SILVA; SILVEIRA; GOMES, 2016), doenças do fígado (PINTO et al., 2017), problemas nos rins (COSTA et al., 2017), diarreia e infecções (RIBEIRO et al., 2017).

O uso de gel dental a base da casca de Aroeira, em doença periodontal experimental em ratos, mostrou efeitos anti-inflamatórios e antimicrobianos, prevenindo a reabsorção óssea alveolar e a perda de peso na periodontite experimental (BOTELHO et al., 2007; BOTELHO et al., 2008a). O extrato hidroalcoólico da casca revelou eficiente atividade antimicrobiana e antiaderente sobre micro-organismos do biofilme dental, e antifúngica sobre cepas de Candida sp. isoladas da cavidade oral (ALVES et al., 2009). Desse modo, as propriedades descritas, corroboram o uso indígena de $M$. urundeuva indicado pelos Fulni-ô.

Os extratos das folhas demonstram ainda bioatividade da planta para inibição bacteriana tanto em células planctônicas quanto no biofilme microbiano (GAETTI-JARDIM JÚNIOR et al., 2011 ), capacidade de alteração da viabilidade dos fibroblastos gengivais humanos (MACHADO et al., 2016), bem como efeito significativo sobre Streptococcus mutans no biofilme oral de ratos, diminuindo a acumulação desta bactéria e a desmineralização do esmalte (MENEZES et al., 2010). Viana, Bandeira e Matosa (2003) elucidaram também a propriedade analgésica da aroeira, a qual endossa o uso tradicional.

\section{Aroeira vermelha (Schinus terebinthifolius Raddi)}

Nativa da América do Sul, S. terebinthifolius, conhecida também como pimenta brasileira, aroeira-da-praia e aroeira-de-remédio, possui hábito arbustivo a arbóreo, com ocorrência confirmada nas regiões Centro-Oeste, Nordeste, Sudeste e Sul do Brasil (MILLER; CHAMBLISS; LOEWENSTEIN, 2015; SILVA-LUZ; PIRANI, 2015; PATOCKA; ALMEIDA, 2017). Dentre os fins medicinais populares da aroeira vermelha está a utilização para diabetes, colesterol, doenças da próstata (MOTA; DIAS, 2012), infecção, gastrite e câncer (PALHETA et al., 2017).

Indicada pela etnia indígena Guarani Mbya para sapinho na boca de criança, cientificamente monilíase oral (STRAMANDINOLI et al., 2010), o 
extrato das folhas de $S$. terebinthifolius possui propriedades comprovadas para essa finalidade no trabalho de Barbieri et al. (2014). Os autores mostraram a eficiência da espécie na inibição de biofilmes in vitro formado por $S$. mutans e Candida albicans, sendo este último fungo o principal agente causador da monilíase oral (CORONADO-CASTELLOTE; JIMÉNEZ-SORIANO, 2013). A ação antifúngica contra outras espécies do gênero Candida, $C$. tropicalis e $C$. krusei também foi encontrada por Alves et al. (2012) e Abílio et al. (2014), respectivamente.

Os bochechos à base de extrato de aroeira vermelha em pacientes com gengivite crônica mostraram-se eficientes no tratamento da doença, demonstrando ação antimicrobiana e anti-inflamatória (LINS et al., 2013). Outros benefícios para a cavidade oral podem estar associados a testes realizados com $S$. terebinthifolius, os quais mostram potencial antisséptico (MELO et al., 2014) e cicatrizante (SCHEIBE et al., 2016).

\section{Malva (Malva sp.)}

Malva sylvestris pode ser encontrada na Europa, África e América, frequente nos campos (COSTA, 2002; SIMÕES et al., 2004). A espécie é citada em diversos estudos etnobotânicos, sendo popularmente usada por suas propriedades anti-inflamatórias e antimicrobianas (GUARRERA, 2005; MENDES; MACHADO; FALKENBERG, 2006; MOREIRA; FERREIRA; HASHIZUME, 2012). Pesquisas realizadas acerca de seu uso no controle de bactérias presentes no biofilme dental, bem como sobre a atividade antiaderente de micro-organismos formadores da placa bacteriana, corroboram a indicação popular (TORRES et al., 2000; BUFFON et al., 2001 ; ALVES et al., 2009).

Os índios Kaingang-Xapecó utilizam a malva no combate às dores de dente, corroborando com estudos que demonstram seu uso amplo nas doenças inflamatórias da mucosa, biofilme dental e abscessos dentários (TORRES et al., 2000; BUFFON et al., 2001 ; SIMÕES et al., 2004; OLIVEIRA et al., 2007). Paralelamente, no estudo realizado por Loddi e Otuki (2008), verificou-se que o extrato hidroalcoólico das flores e folhas potencializa o processo de cicatrização de lesão do palato, sugerindo ainda que a planta tem ação anti-inflamatória e cicatrizante pela ação sinérgica de seus compostos.

\section{Joazeiro (Ziziphus joazeiro Mart.)}

Presente predominantemente na região Nordeste do Brasil, $Z$. joazeiro é conhecida por juazeiro, juá ou laranjeira-do-vaqueiro e caracteriza-se como um dos representantes mais notáveis do bioma Caatinga (LORENZI; MATOS, 2002; ALBUQUERQUE et al., 2010). A espécie em sua integridade possui vasto uso popular como antisséptico bucal, para tratamentos dermatológicos, do sistema respiratório e digestório, 
sendo ainda relatado o uso como cicatrizante e para o tratamento de micoses (KATO; OHARA; NISHITAMI, 1998; ALMEIDA et al., 2005; CRUZ et al., 2007; ALBUQUERQUE; LUCENA; CUNHA, 2008).

Indicada pela etnia indígena Fulni-ô para limpeza dos dentes, o extrato das cascas de $Z$. joazeiro possui propriedades comprovadas para essa finalidade nos trabalhos de Cruz et al. (2007), Fejerskov e Kidd (2009), Cavalcante (2010) e Silva et al. (2011). Estes estudos mostram a presença de flavonoides, fenóis, taninos, saponinas, bem como, atividade antioxidante com capacidade de eliminação de radicais livres. Além disso, o extrato aquoso da casca foi sinérgico em combinação com gentamicina ou amicacina contra Enterobacter aerogenes e em combinação com gentamicina contra Streptococcus aureus. Estudos também evidenciaram a eficiência da espécie na inibição de biofilmes (MATOS, 1997; CAVALCANTE, 2010).

Alviano et al. (2008) avaliaram in vitro a toxicidade aguda e as atividades antioxidante e antimicrobiana de $Z$. joazeiro sobre microorganismos formadores do biofilme dental e concluíram que o extrato (etanólico ou aquoso) possui potencial antioxidante, baixa toxicidade e ação antimicrobiana sobre as bactérias planctônicas pesquisadas, principalmente sobre a Porphyromonas gingivalis. Brito et al. (2015), pesquisando o extrato hidroalcoólico das folhas do joazeiro, consideraram que é um produto natural promissor no desenvolvimento de fitomedicamentos contra infecções resistentes a drogas antimicrobianas.

\section{Alecrim (Lippia sp.)}

Lippia sp. possui ampla distribuição geográfica, sendo facilmente encontrada em países tropicais e conhecida popularmente como erva cidreira, chá de tabuleiro, cidrila, alecrim selvagem, cidreira brava e carmelitana (LORENZI; MATOS, 2002). Diversas espécies de Lippia são usadas na medicina popular por suas atividades biológicas e terapêuticas (GOMES; NOGUEIRA; MORAES, 2011 ; GOMES et al., 2016).

Estudos em diversas áreas do conhecimento vêm confirmando as atividades terapêuticas propaladas na medicina popular. Foi demonstrada atividade antibacteriana em gengivite e placa dentária com uso de óleo essencial de Lippia sidoides Cham. (LÔBO et al., 2010; PEREIRA et al., 2013), bem como atividade antifúngica obtida também do seu extrato etanólico contra cepas resistentes de Candida sp., isoladas de secreções vaginais (FARIAS-JÚNIOR et al., 2012). Outros trabalhos farmacológicos com o alecrim já evidenciaram também seu efeito analgésico, antiinflamatório (VIANA et al., 1998) e como relaxante muscular (GOMES; NOGUEIRA; MORAES, 2011 ).

A indicação odontológica indígena da espécie pela etnia Fulni-ô foi a utilização da folha para dor de dente. Lippia sp. previne a reabsorção óssea alveolar na periodontite experimental em ratos comprovada em 
estudos (BOTELHO et al., 2007; BOTELHO et al., 2008b), fortalecendo, portanto, o uso indígena.

\section{Demais espécies}

Apesar de doze etnoespécies não terem sido averiguadas farmacologicamente quanto a seus benefícios para saúde bucal, oito possuem propriedades médicas comprovadas, algumas das quais corroboram o uso indígena, a exemplo do efeito anti-inflamatório para o rosário-de-lavoura (Coix lacryma-jobi L.) (HUANG et al., 2014), as atividades anti-inflamatórias, antibacterianas e relaxante muscular da emburana de cheiro [Amburana cearensis (Allemão) A.C.Sm.] (ARARUNA et al., 2013; LIMA et al., 2013; SANTOS et al., 2014) e a atividade antimicrobiana da curunilha (S. buxifolia) (MOREL et al., 2005).

O estudo de Bezerra (2008) acerca das propriedades da jurema preta [Mimosa tenuiflora (Willd.) Poir.] revela eficácia contra bactérias grampositivas, gram-negativas e fungos dermatófitos. A abundância de taninos e flavonoides detectados no extrato acetato de etila de $M$. tenuiflora é a provável responsável por sua ação antimicrobiana (RIVERA-ARCE et al., 2007; BITENCOURT et al., 2014). Pesquisas conduzidas com o guiné ( $P$. alliacea) apresentam propriedades anti-inflamatórias, antimicrobianas e antifúngicas (OLIVEIRA, 2012; SOUZA et al., 2015).

A pariparoba ( $P$. umbellata) possui ações anti-inflamatórias e antifúngicas descritas na literatura e comprovadas por Cushnie e Lamb (2005). O pessegueiro-do-mato [Prunus myrtifolia (L.) Urb.] demonstrou atividade frente a fungos patogênicos como Cladosporium sphaerospermum e C. cladosporioides. Estudos de Jäger, Hutchings e Van Staden (1996), Lindsey et al. (1999) e Sens (2002) descrevem o potencial do extrato das folhas do fumo-brabo (S. mauritianum) no tratamento de dores de cabeça, doenças inflamatórias e dismenorreia, bem como a capacidade de inibição da cicloxigenase, que estão envolvidas nos processos inflamatórios e são responsáveis pela sensação de dor, corroborando assim, o uso indígena para dor de dente.

Com relação às outras etnoespécies, duas não foram identificadas cientificamente, a cana-frista e a batata doce, inviabilizando desse modo a busca por propriedades farmacológicas, enquanto para o coqueirojerivá [Syagrus romanzoffiana (Cham.) Glassman] e para o esporão-degalo [Celtis ehrenbergiana (Klotzsch) Liebm.] não foram encontradas propriedades médicas descritas na literatura, evidenciando, portanto, a necessidade de pesquisas com essas espécies.

\section{Conclusão}

Utilizando metodologia de revisão sistemática da literatura científica, descrevemos a riqueza do conhecimento botânico medicinal indígena do 
Brasil e sua eficácia na profilaxia e tratamento bucal. No entanto, fica patente a necessidade de mais estudos direcionados à área de saúde oral, tendo em vista a riqueza da flora e dos saberes tradicionais no país.

\section{Referências bibliográficas}

ABÍliO, V. M. F.; MESQUITA, B. S.; SILVA, E. D.; CARVALHO, F. V. Q.; MACÊDO, L. L. A.; CASTRO, R. D. Atividade antifúngica de produtos naturais indicados por raizeiros para tratamento de candidíase oral. Revista Cubana de Estomatología, Havana, v. 51, n. 3, p. 259-269, 2014.

ALBUQUERQUE, U. P.; LUCENA, R. F. P.; CUNHA, L. V. F. C. Métodos e técnicas para coleta de dados etnobotânicos. In: ALBUQUERQUE, U. P.; LUCENA, R. F. P.; CUNHA, L. V. F. C. Métodos e técnicas na pesquisa etnobotânica. Recife, 2.ed., Comunigraf, 2008. p.324.

ALBUQUERQUE, U. P.; SOLDATI, G. T.; SIEBER, S. S.; MEDEIROS, P. M.; SÁ, J. C.; SOUZA, L. C. Rapid ethnobotanical diagnosis of the Fulni-ô Indigenous lands (NE Brazil): floristic survey and local conservation priorities for medicinal plants. Environment, Development and Sustainability, Holanda, v. 1, p. 277-292, 2010.

ALELUIA, C. M.; PROCÓPIO, V. C.; OLIVEIRA, M. T. G.; FURTADO, P. G. S.; GIOVANNINI, J. F. G.; MENDONÇA, S. M. S. Fitoterápicos na odontologia. Revista de Odontologia da Universidade Cidade de São Paulo, São Paulo, v. 27, n. 2, p. 126$134,2015$.

ALENCAR, C.O.; MICLOS, P. V.; CARVALHO, R. B.; CORTELLI, J. R. Fluorose dentária e condição periodontal de crianças indígenas do município de Aracruz, ES. Brazilian Journal of Periodontology, Brasil, v. 21, n. 4, p. 80-85, 2011.

ALMEIDA, C. F. C. B. R.; LIMA E SILVA, T. C.; AMORIM, E. L. C.; MAIA, M. B.; ALBUQUERQUE, U. P. Life strategy and chemical composition as predictors of the selection of medicinal plants from the Caatinga (Northeast Brazil). Journal of Arid Environments, v. 62, n. 1; p. 127-42, 2005.

ALVES FILHO, P.; SANTOS, R. V.; VETTORE, M. V. Fatores associados a cárie dental e doença periodontal em indígenas na América Latina: Revisão sistemática. Revista Panamericana de Salud Pública, Washington, v. 35, n. 1, p. 67-77, 2014.

ALVES, L. A.; FREIRES, A. I.; SOUZA, T. M. P.; CASTRO, R. D. In vitro activity of Schinus terebinthifolius (Brazilian Pepper Tree) on Candida tropicalis growth and cell wall formation. Acta Odontológica Latinoamericana, Buenos Aires, v. 25, n. 3, p. 287$292,2012$. 
ALVES, P. M.; QUEIROZ, L. M. G.; PEREIRA, J. V.; PEREIRA, M. S. V. Atividade antimicrobiana, antiaderente e antifúngica in vitro de plantas medicinais brasileiras sobre microrganismos do biofilme dental e cepas do gênero Candida. Revista da Sociedade Brasileira de Medicina Tropical, Uberaba, v. 42, n. 2, p. 222-224, 2009.

ALVIANO, W. S.; ALVIANO, D. S.; DINIZ, C. G.; ANTONIOLLI, A. R.; ALVIANO, C. S.; FARIAS, L. M.; CARVALHO, M. A. R.; SOUZA, M. M. G.; BOLOGNESE, A. M. In vitro antioxidant potential of medicinal plant extracts and their activities against oral bacteria based on Brazilian folk medicine. Archives of Oral Biology, v. 53, p. 545$52,2008$.

ARANTES, R. Saúde bucal dos povos indígenas no Brasil: Panorama atual e perspectivas. In: COIMBRA JÚNIOR, C. E. A.; SANTOS, R. V.; ESCOBAR, A. L. (orgs.). Epidemiologia e saúde dos povos indígenas no Brasil. Rio de Janeiro: FIOCRUZ. Rio de Janeiro: ABRASCO, 2005. p. 49-72.

ARARUNA, S. M.; SILVA, A. H.; CANUTO, K. M.; SILVEIRA, E. R.; LEAL, L. K. A. Influence of process conditions on the physicochemical characteristics of cumaru (Amburana cearensis) powder produced by spray drying. Revista Brasileira de Farmacognosia, Curitiba, v. 23, n. 1, p. 132-137, 2013.

ARROYAVE, J. U. A.; ISÁGAMA, M. E. Flora etnoodontológica de las comunidades indígenas embera del Atrato Medio antioqueño. Revista Facultad de Odontología Universidad de Antioquia, Medelim, v. 23, n. 2, p. 321-333, 2012.

BARBIERI, D. S. V.; TONIAL, F.; LOPEZ, P. V. A.; MAIA, B. H. L. N. S.; SANTOS, G. D.; RIBAS, M. O.; GLIENKE, C.; VICENTE, V. A. Antiadherent activity of Schinus terebinthifolius and Croton urucurana extracts on in vitro biofilm formation of Candida albicans and Streptococcus mutans. Archives of Oral Biology, v. 59, p. 887-896, 2014.

BARBOSA, P. R. N.; NASCIMENTO, R. L. Prevalência de cárie dentária em escolares de 12 anos de uma escola pública do município do Rio de Janeiro. Academus Revista Científica da Saúde, Rio de Janeiro, v. 2, n. 1, p. 1-11, 2017.

BASTA, P. C.; ORELLANA, J. D.Y.; ARANTES, R. Perfil epidemiológico dos povos indígenas no Brasil: notas sobre agravos selecionados. In: GARNELO, L.; PONTES, A. L. (orgs.). Saúde Indígena: uma introdução ao tema. Brasília: Ministério da Educação, Secretaria de Educação Continuada, Alfabetização, Diversidade e Inclusão; Unesco, 2012. p. 60-106.

BERTANHA, W. D. F. F.; CAVAlCANTE, G. M. S. L.; CAVALCANTI, A. L.; ARRUDA, T. A.; D'ÁVILA, S. Atenção à Saúde Bucal nas Comunidades Indígenas: Evolução e Desafios: Uma Revisão de Literatura. Revista Brasileira de Ciências da Saúde, João Pessoa, v.16, n.1, p.105-112, 2012.

BEZERRA, D. A. C. Estudo fitoquímico, bromatológico e microbiológico de Mimosa tenuiflora (Wild) Poiret e Piptadenia stipulacea (Benth) Ducke. 2008. $63 \mathrm{f}$. 
Dissertação (Mestrado em Zootecnia) - Programa de Pós-Graduação em Zootecnia, Universidade Federal de Campina Grande. Campina Grande, 2008.

BITENCOURT, M. A. O.; SOUZA LIMA, M. C. J.; TORRES-RÊGO, M.; FERNANDES, J. M.; SILVA-JÚNIOR, A. A.; TAMBOURGI, D. V.; ZUCOLOTTO, S. M.; FERNANDES-PEDROSA, M. F. Neutralizing Effects of Mimosa tenuiflora extracts against Inflammation caused by Tityus serrulatus Scorpion Venom. Biomed Research International, v. 2014, p. 1-8, 2014.

BORBA, A. M.; MACEDO, M. Plantas medicinais usadas para a saúde bucal pela comunidade do bairro Santa Cruz, Chapada dos Guimarães, MT, Brasil. Acta Botanica Brasilica, Rio de Janeiro v. 20, n. 4, p. 771-782, 2006.

BOTELHO, M. A.; RAO, V. S.; CARVALHO, C. B. M.; BEZERRA-FILHO, J. G.; FONSECA, S. G. C.; VALE, M. L.; MONTENEGRO, D.; CUNHA, F.; RIBEIRO, R. A.; BRITO, G. A. Lippia sidoides and Myracrodruon urundeuva gel prevents alveolar bone resorption in experimental periodontitis in rats. Journal of Ethnopharmacology, v. 113, p. 471-478, 2007.

BOTELHO, M. A.; RAO, V. S.; MONTENEGRO, D.; BANDEIRA, M. A.; FONSECA, S. G.; NOGUEIRA, N. A.; RIBEIRO, R. A.; BRITO, G. A. Effects of a Herbal Gel containing Carvacrol and Chalcones on Alveolar Bone Resorption in Rats on Experimental Periodontitis. Phytotherapy Research, v. 22, p. 442-449, 2008a.

BOTELHO, R. J.; EFE, J. A.; TEIS, D.; EMR, S. D. Assembly of a Fab1 Phosphoinositide Kinase Signaling Complex Requires the Fig4 Phosphoinositide Phosphatase. Molecular Biology of the Cell, v. 19, n. 10, 2008b.

BRITO, S. M. O.; COUTINHO, H. D.; TALVANI, A.; CORONEL, C.; BARBOSA, A. G.; VEJA, C.; FIGUEREDO, F. G.; TINTINO, S. R.; LIMA, L. F.; BOLIGON, A. A.; ATHAYDE, M. L.; MENEZES, I. R. Analysis of bioactivities and chemical composition of Ziziphus joazeiro Mart. using HPLC-DAD. Food Chemistry, v. 186, n. 1, p. 185-191, 2015.

BUFFON, M. D. C. M.; COSTA LIMA, M. L., GALARDA, I.; COGO, L. Avaliação da eficácia dos extratos de Malva sylvestris, Calendula officinalis, Plantago major e Curcuma zedoarea no controle do crescimento das bactérias da placa dentária. Estudo "in vitro". Revista Visão Acadêmica, Curitiba, v. 2, p. 31-38, 2001.

CARNEIRO, M. C. G.; SANTOS, R. V.; GARNELO, L.; REBELO, M. A. B.; COIMBRA JR., C. E. A. Cárie dentária e necessidade de tratamento odontológico entre os índios Baniwa do Alto Rio Negro, Amazonas. Ciência \& Saúde Coletiva, Rio de Janeiro, v. 13, n. 6, p. 1895-1992, 2008.

CAVAlCANTE, A. L. F. A. Plantas medicinais e saúde bucal: estudo etnobotânico, atividade antimicrobiana e potencial para interação medicamentosa. 2010. $209 \mathrm{f}$. Dissertação (Mestrado em Odontologia) - Programa de Pós-Graduação em Odontologia, Universidade Federal da Paraíba - UFPB. João Pessoa, 2010. 
COAN, C. M.; MATIAS, T. A utilização das plantas medicinais pela comunidade indígena de Ventarra Alta- RS. SaBios - Revista de Saúde e Biologia, Campo Mourão, v. 9, n. 1, p. 11-19, 2014.

CORONADO-CASTELLOTE, L.; JIMÉNEZ-SORIANO, Y. Clinical and microbiological diagnosis of oral candidiasis. Journal of Clinical and Experimental Dentistry, v. 5, n. 5, p. 279-286, 2013.

COSTA, A. F. Farmacognosia, 5 ed. Lisboa: Fundação Caloust Gulbekian, v.2, Manuais Universitários, 2002. 1120p.

COSTA, I. B. C.; BONFIM, F. P.G.; PASA, M. C.; MONTERO, D. A.V. Ethnobotanical survey of medicinal flora in the rural community Rio dos Couros, state of Mato Grosso, Brazil. Boletín Latinoamericano y del Caribe de Plantas Medicinales y Aromáticas, v. 16, n. 1, p. 53-67, 2017.

CRUZ, M. C. S.; SANTOS, P. O.; BARBOSA JR., A. M.; MÉLO, D. L. F. M.; ALVIANO, C. S.; ANTONIOLli, A. R.; ALVIANO, D. S.; TRINDADE, R. C. Antifungal activity of Brazilian medicinal plants involved in popular treatment of mycoses. Journal of Ethnopharmacology, v. 111, n. 2, p. 409-412, 2007.

CUSHNIE, T. P. T.; LAMB, A. J. Antimicrobial activity of flavonoids. International Journal of Antimicrobial Agents, v. 26, n.5, p. 343-356, 2005.

FARIAS-JÚNIOR, P. A.; RIOS, M. C.; MOURA, T. A.; ALMEIDA, R. P.; ALVES, P. B.; BLANK, A. F.; FERNANDES, R. P. M.; SCHER, R. Leishmanicidal activity of carvacrol-rich essential oil from Lippia sidoides Cham. Biological Research, v. 45, n. 4, p. 399-402, 2012.

FEJERSKOV, O.; KIDD, E. Dental Caries: The Disease and Its Clinical Management. John Wiley e Sons, 640 p., 2009.

FLORA DO BRASIL 2020 [em construção]. Jardim Botânico do Rio de Janeiro. Disponível em: <http://floradobrasil.jbrj.gov.br/>. Acesso em 3 jul. 2017.

FUNDAÇÃO NACIONAL DO ÍNDIO - Funai. Índios no Brasil - Terras indígenas. Disponível em: < http://www.funai.gov.br/index.php/indios-no-brasil/terras-indigenas $>$. Acesso em 3 jul. 2017.

GAETTI-JARDIM JÚNIOR, E.; LANDUCCI, L. F.; ARAFAT, O. K. K.; RANIERI, R. V.; RAMOS, M. M. B.; CIESIELSKI, F. I. N.; SCHWEITZER, C. M.; OKAMOTO, A. C. Antimicrobial Activity of Six Plant Extracts from the Brazilian Savanna on Periodontal Pathogens. International Journal of Dontostomatology, v. 5, n. 3, p. 249-256, 2011.

GOMES, P. R. B.; SILVA, A. L. S.; PINHEIRO, H. A.; CARVALHO, L. L.; LIMA, H. S.; SILVA, E. F.; SILVA, R. P.; LOUZEIRO, C. H.; OLIVEIRA, M. B.; FILHO, V. E. M. Avaliação da atividade larvicida do óleo essencial do Zingiber officinale 
Roscoe (gengibre) frente ao mosquito Aedes aegypti. Revista Brasileira de Plantas Medicinais, Botucatu, v. 18, n. 2, p. 597-604, 2016.

GOMES, S. V. F.; NOGUEIRA, P. C. L.; MORAES, V. R. S. Aspectos químicos e biológicos do gênero Lippia enfatizando Lippia gracilis Schauer. Eclética Química, Araraquara, v. 36, n. 1, p. 64-77, 2011.

GUARRERA, P. M. Traditional phytotherapy in Central Italy (Marche, Abruzzo, and Latium). Fitoterapia, Valencia, v. 76, n. 1, p.1-25, 2005.

HAVERROTH, M. Etnobotânica, saúde e povos indígenas. In: HAVERROTH, M. (org.). Etnobiologia e Saúde de Povos Indígenas. Recife, PE: NUPEEA, 2013. p.37-64.

HAVERROTH, M. Kaingang um Estudo Etnobotânico: O uso e a classificação das plantas na Área Indígena Xapecó (Oeste de SC). 1997. 182p. Dissertação (Mestrado em Antropologia Social) - Programa de Pós-Graduação em Antropologia Social, Universidade Federal de Santa Catarina - UFSC. Florianópolis, 1997.

HUANG, D.; WU, C. ; SHIH ,C.; LIU, C.; SHIH, P.; SHIEH, T.; LIN, C.; CHIANG, W.; HSIA, S. Application of the solvent extraction technique to investigation of the antiinflammatory activity of adlay bran. Food Chemistry, v. 145, n. 2014, p. 445-453, 2014.

INSTITUTO BRASILEIRO DE GEOGRAFIA E ESTATÍSTICA - IBGE. Indígenas. 2010. Disponível em: < http://indigenas.ibge.gov.br/graficos-e-tabelas-2.html >. Acesso em 1 jul. 2017.

IPNI (The International Plant Names Index). 2016. Disponível em: <http://www.ipni.org/ipni/plantnamesearchpage.do $>$. Acesso em 3 jul. 2017.

JÄGER, A. K.; HUTCHINGS, A.; VAN STADEN, J. Screening of Zulu medicinal plants for prostaglandin-synthesis inhibitors. Journal of Ethnopharmacology, v. 52, p. 95-100, 1996.

KATO, E. T. M.; OHRA, M. T.; NISHITAMI, M. Evaluation of antimicrobial property of Ziziphus joazeiro Martius. Lecta, v. 16, n. 2, p. 75-85, 1998.

KFFURI, C. W.; LOPES, M. A.; MING, L. C.; ODONNE, G.; KINUPP, V. F. Antimalarial plants used by indigenous people of the Upper Rio Negro in Amazonas, Brazil. Journal of Ethnopharmacology, v. 178, n. 2016, p. 188-198, 2016.

LIMA, L. R.; CAVAlCANTE, R. R. L.; MARTINS, M. C. C.; PARENTE, D. M.; CAVALCANTE, A. A. M. C. Avaliação da atividade antiedematogênica, antimicrobiana e mutagênica das sementes de Amburana cearensis (A. C. Smith) (Imburana-de-cheiro). Revista Brasileira de Plantas Medicinais, Botucatu, v. 15, n. 3, p. 415-422, 2013.

LINDENMAIER, D. S.; PUTZKE J. Estudo etnobotânico em três comunidades Mbya/Guarani na região central do Rio Grande do Sul, Brasil. Caderno de Pesquisa, Série Biologia, Santa Cruz do Sul, v. 23, n. 3, p. 6-19, 2011. 
LINDSEY, K.; JÄGER, A. K.; RAIDOO, D. M.; VAN STADEN, J. Screening of plants used by Southern African traditional healers in the treatment of dysmenorrhoea for prostaglandin-synthesis inhibitors and uterine relaxing activity. Journal of Ethnopharmacology, v. 64, p. 9-14, 1999.

LINS, R.; VASCONCELOS, F. H. P.; LEITE, R. B.; COELHO-SOARES, R. S.; BARBOSA, D. N. Avaliação clínica de bochechos com extratos de aroeira (Schinus terebinthifolius) e camomila (Matricaria recutita L.) sobre a placa bacteriana e a gengivite. Revista Brasileira de Plantas Medicinais, Botucatu, v. 15, n. 1, p. 112-120, 2013.

LÔBO, K. M. S.; ATHAYDE, A. C. R.; SILVA, A. M. A.; RODRIGUES, F. F. G.; LÔBO, I. S.; BEZERRA, D. A. C.; COSTA, J. G. M. Avaliação da atividade antibacteriana e prospecção fitoquímica de Solanum paniculatum Lam. e Operculina hamiltonii (G. Don) D. F. Austin \& amp; Staples, do semiárido paraibano. Revista Brasileira de Plantas Medicinais, Botucatu, v. 12, n. 2, p. 227-233, 2010.

LODDI, A. M.; OTUKI, M. F. Avaliação pré-clínica do potencial antiinflamatório e cicatrizante da Malva Sylvestris linn. em alterações bucais. 2008. 122 f. Dissertação (Mestrado em Farmacologia) - Programa de Pós-graduação em Farmacologia, Setor de Ciências Biológicas, Universidade Federal do Paraná - UFPR. Curitiba, 2008.

LORENZI, H.; MATOS, F. J. A. Plantas medicinais no Brasil: nativas e exóticas. São Paulo: Instituto Plantarum de Estudos da Flora, 2002.

LUCIANO, G. S. Saúde indígena. Em: LUCIANO, G. S. (org.). O índio Brasileiro: o que você precisa aprender sobre os povos indígenas no Brasil hoje. Brasília, DF: Ministério da Educação Continuada, Alfabetização e Diversidade; LACED/Museu Nacional, 2006.

MACHADO, A. C.; SOUZA, L. P.; SALDANHA, L. L.; PIERONI, L. G.; MATOS, A. A.; OLIVEIRA, F. A. "Aroeira" (Myracrodruon urundeuva) metanol extract: the relationship between chemical compounds and cellular effects. Pharmaceutical Biology, v. 55, n. 11, p. 2737-2741, 2016.

MATOS, F. J. A. Living pharmacies: ciência e cultura. Journal of the Brazilian Association for the Advancement of Science, Brasil, v. 49, p. 409-412, 1997.

MELO, M. C. S. C.; GADELHA, D. N. B.; OLIVEIRA, T. K. B.; BRANDT, C. T. Alcohol extract of Schinu sterebinthifolius Raddi (anacardiaceae) as a local antimicrobial agent in severe autogenously fecal peritonitis in rat. Acta Cirúrgica Brasileira, São Paulo, v. 29, n. 1, p. 52-56, 2014.

MENDES, B. G.; MACHADO, M. J.; FALKENBERG, M. Triagem de glicolipídios em plantas medicinais. Revista Brasileira de Farmacognosia, Curitiba, v. 16, n. 4, p. 568$575,2006$. 
MENDES, I. O Uso das ervas medicinais na atualidade Kaingang da Terra Indígena Xapecó, Santa Catarina, Brasil. 2015. 35 f. Monografia (Graduação em Licenciatura Intercultural Indígena do Sul da Mata Atlântica, Terminalidade Gestão Ambiental) Universidade Federal de Santa Catarina - UFSC. Florianópolis, 2015.

MENEZES, T. E. C.; DELBEM, A. C. B.; BRIGHENTI, F. L.; OKAMOTO, A. C.; GAETTI-JARDIM JR, E. Protective efficacy of Psidium cattleianum and Myracrodruon urundeuva aqueous extracts against caries development in rats. Pharmaceutical Biology, v. 48 , n. 3, p. 300-305, 2010.

MILlER, J. H.; CHAMBLISS, E. B.; LOEWEnSteIN, N. J. A Field Guide for the Identification of Invasive Plants in Southern Forests. United States: Department of Agriculture, 2015. 136p.

MOREIRA, M. J. S.; FERREIRA, M. B. C.; HASHIZUME, L. N. Avaliação In Vitro da Atividade Antimicrobiana dos Componentes de um Enxaguatório Bucal contendo Malva. Pesquisa Brasileira em Odontopediatria e Clínica Integrada, Campina Grande, v. 12, n. 4, p. 505-509, 2012.

MOREL, F. A.; MALDANER, G.; ILHA, V.; MISSAU, F.; SILVA, U. F.; DALCOL, II. 86 Cyclopeptide alkaloids from Scutia buxifolia Reiss and their antimicrobial activity. Phyto, v. 66, p. 2571-2576, 2005.

MOTA, R. S.; DIAS, H. M. Quilombolas e recursos florestais medicinais no sul da Bahia, Brasil. Interações, Campo Grande, v. 13, n. 2, p.151-159, 2012.

OLIVEIRA, F. Q.; GOBIRA, B.; GUIMARÃES, C.; BATISTA, J.; BARRETO, M.; SOUZA, M. Espécies vegetais indicadas na odontologia. Revista Brasileira de Farmacognosia, Curitiba, v. 17, n. 3, p. 466-476, 2007.

OLIVEIRA, F. R. Avaliação antifúngica, farmacognóstica e toxicológica sazonal de Petiveria alliacea L. (PHYTOLACCACEAE). 2012. 108 f. Dissertação (Mestrado em Ciências Farmacêuticas) - Programa de Pós-Graduação em Ciências Farmacêuticas, Universidade Federal do Pará - UFPA. Belém, 2012.

OLIVEIRA, P. C.; BRAGA, J. Ethnobotany of Borari-Arapiuns indigenous people, Amazon, Brazil. Journal of Medicinal Plants Studies, v. 5, n. 1, p. 164-170, 2017.

PALHETA, I. C.; TAVARES MARTINS, A. C. C.; LUCAS, F. C. A.; JARDIM, M. A. G. Ethnobotanical study of medicinal plants in urban home gardens in the city of Abaetetuba, Pará state, Brazil. Boletín Latinoamericano y del Caribe de Plantas Medicinales y Aromáticas, v. 16, n. 3, p. 206-262, 2017.

PATOCKA, J.; ALMEIDA, J. D. Brazilian Pepper Tree: Review of Pharmacology. Military Medical Science Letters, v. 86, n. 1, p. 32-41, 2017. 
PEREIRA, S. L. S.; PRAXEDES, Y. C. M.; BASTOS, T. C.; ALENCAR, P. N. B.; COSTA, F. N. Clinical effect of a gel containing Lippia sidoides on plaque and gingivitis control. European Journal of Dentistry, v. 7, p. 28-34, 2013.

PINTO, J. S.; OLIVEIRA, A. K. M.; FERNANDES, V. MATIAS, R. Ethnobotany and popular culture in the use of plants in settlements on the southern edge of southern pantanal Mato Grosso. Bioscience Journal, v. 33, n. 1, p. 193-203, 2017.

RIBEIRO, R. V.; BIESKI, I. G. C.; BALOGUN, S. O.; MARTINS, D. T. O. Ethnobotanical study of medicinal plants used by ribeirinhos in the North Araguaia microregion, Mato Grosso, Brazil. Journal of Ethnopharmacology, v. 205, p. 69-102, 2017.

RIVERA-ARCE, E.; GATTUSO, M.; ALVARADO, R.; ZÁRATE E.; AGUERO, J.; FERIA, I.; LOZOYAA, X. Pharmacognostical studies of the plant drug Mimosae tenuiflorae cortex. Journal of Ethnopharmacology, v. 113, n. 3, p. 400-408, 2007.

ROCHA, R.; MARISCO, G. Estudos etnobotânicos em comunidades indígenas no Brasil. Revista Fitos, Rio de Janeiro, v. 10, n. 2, p. 95-219, 2016.

SANTOS, J. X.; REIS, A. R. S.; PARRY, S. M.; LEÃO, F. M.; CARVALHO, C. C. Caracterização etnobotânica de essências florestais com fins medicinais utilizadas pela etnia Xipaya no município de Altamira-PA. Biota Amazônica, Macapá, v. 6, n. 2, p. 18, 2016.

SANTOS, L. O.; REIS, M. R.; OGAVA, L. E.; MAPELI, A. M.; MACHADO, L. L.; LEÃO, K. V. Avaliação de atividade antioxidante e fenóis totais dos extratos das folhas e da casca de Amburana cearenses. Orbital: The Electronic Journal of Chemistry, v.6, 2014.

SANTOS-LIMA, T. M.; SANTOS, D. R. V.; SOUZA, R. M.; BASTOS, N. G.; VANNIER-SANTOS, M. A.; NUNES, E. S.; DIAS-LIMA, A. G. Medicinal plants with antiparasitic action: Traditional knowledge of the Kantaruré ethnic group, Baixa das Pedras village, Bahia, Brazil. Revista Brasileira de Plantas Medicinais, Botucatu, v. 18, n. 1, p. 240-247, 2016.

SCHEIBE, C. L.; RIBAS-FILHO, J. M.; CZECZKO, N. G.; MALAFAIA, O.; BARBOZA, L. E. D.; RIBAS, F. M.; WENDLER, E. TORRES, O.; LOVATO, F. C.; SCAPINI, J. G. S. Schinus terebinthifolius Raddi (Aroeira) and Orbignya phalerata Mart. (Babassu) effect in cecorrahphy healing in rats. Acta Cirúrgica Brasileira, São Paulo, v. 31, n. 6, p. 402-410, 2016.

SENS, S. L. Alternativas para a auto-sustentabilidade dos Xokleng da terra indígena Ibirama. 2002. 366 f. Dissertação (Mestrado em Engenharia de Produção) - Universidade Federal de Santa Catarina - UFSC. Florianópolis, 2002. 
SILVA, F. J.; SILVEIRA, A. P.; GOMES, V. S. Plantas medicinais e suas indicações ginecológicas: estudo de caso com moradoras de Quixadá, CE, Brasil. Revista Brasileira de Biociências, Porto Alegre, v. 14, n. 3, p. 193-201, 2016.

SILVA, T. C. L.; ALMEIDA, C. C. B. R.; FILHO, J. V.; SOBRINHO, T. P.; AMORIN, E. L. C.; COSTA, E. P.; ARAÚJO, J. M. Atividades antioxidante e antimicrobiana de Ziziphus joazeiro Mart. (Rhamnaceae): avaliação comparativa entre cascas e folhas. Revista de Ciências Farmacêuticas Básica e Aplicada, Araraquara, v. 32, n. 2, p. 193199, 2011.

SILVA, V.A. Etnobotânica dos Índios Fulni-ô (Pernambuco, Nordeste do Brasil). 2003. 151 f. Dissertação (Mestrado em Biologia Vegetal) - Departamento de Botânica, Universidade Federal de Pernambuco - UFPE. Recife, 2003.

SILVA-LUZ, C. L.; PIRANI, J. R. 2015. Anacardiaceae in Lista de espécies da flora do Brasil. Jardim Botânico do Rio de Janeiro. Disponivel em: <http://floradobrasil.jbrj.gov.br/jabot/floradobrasil/FB115559>. Acesso em 10 jul. 2017.

SIMÕES, C. M. O.; SCHENKEL, E. P.; GOSMANN, G.; MELLO, J. C. P.; MENTZ, L. A.; PETROVICK. P. R. Farmacognosia, da planta ao medicamento. 5 ed Florianópolis: Ed. UFRGS: 2004.

SOUZA, A. P. O.; OLIVEIRA, R. M.; OLIVEIRA, S. F.; FORTUNA, J. L. Atividade antimicrobiana dos sumos de alecrim, aroeira, guiné e mastruz sobre Staphylococcus aureus e Escherichia coli. Scientia Plena, São Cristóvão, v. 7, n. 11, p. 1-9, 2015.

STRAMANDINOLI, R. T.; SOUZA, P. H. C.; WESTPHALEN, F. H.; BISINELLI, J. C.; IGNÁCIO, S. A.; YURGEL, L. S. Prevalência de candidose bucal em pacientes hospitalizados e avaliação dos fatores de risco. Revista Sul-Brasileira de Odontologia, Joinville, v. 7, n. 1, p. 66-72, 2010.

TORRES, C. R. G.; KUBO, C. H.; ANIDO, A. A.; RODRIGUES, J. R. Agentes antimicrobianos e seu potencial de uso na Odontologia. Brazilian Dental Science, São José dos Campos, v. 3, n. 2, p. 43-52, 2000.

VIANA, G. S. B.; BANDEIRA, M. A. M.; MATOSA, F. J. A. Analgesic and antiinflammatory effects of chalcones isolated from Myracrodruon urundeuva Allemão. Phytomedicine, v. 10, p. 189-195, 2003.

VIANA, G. S. B.; VALE, T. G.; RAO, V. S. N.; MATOS, F. J. A. Analgesic and antiinflamatory effects of two chemotypes of Lippia alba: a comparative study. Pharmaceutical Biology, v. 36, n. 5, p. 347-351, 1998. 
Recebido em: 11/06/2018 * Aprovado em: 06/11/2018 * Publicado em: 27/06/2019 